\title{
Erratum: L3MBTL1 recognition of mono- and dimethylated histones
}

Jinrong Min, Abdellah Allali-Hassani, Nataliya Nady, Chao Qi, Hui Ouyang, Yongsong Liu, Farrell MacKenzie, Masoud Vedadi \& Cheryl H Arrowsmith

Nat. Struct. Mol. Biol. 14, 1229-1230 (2007); published online 18 November 2007; corrected after print 18 December 2007

In the version of this article initially published, the "Accession codes" section was missing. The section should read:

Accession codes. Protein Data Bank: Coordinates and structure factors have codes 2PQW, 2RJE and 2RJF (L3MBTL1-H4K20me2 complexes), 2RJD (L3MBTL1 apo structure) and 2RJC (L3MBTL1-MES complex).

The error has been corrected in the HTML and PDF versions of the article. 